\title{
(2) OPEN ACCESS \\ Optic disc and peripapillary vessel density measured with optical coherence tomography angiography and its associations in Chinese adults: a large population- based study
}

\author{
Ming Ming Zhu 지, ${ }^{1}$ Bonnie N K Choy 다, ${ }^{1}$ Qi Sheng You, ${ }^{2}$ \\ Jonathan Cheuk Hung Chan $\oplus^{\circ},{ }^{3}$ Alex L K Ng @,${ }^{1}$ Kendrick Shih, \\ Janice Jing Chee Cheung (ㄷ, , Jasper Ka Wai Wong 이, ${ }^{1}$ Jennifer Shum, ${ }^{1}$ \\ Michael Y Ni, ${ }^{4,5}$ Jimmy Shiu-Ming Lai, ${ }^{1}$ Gabriel M Leung, ${ }^{6}$ lan Y Wong (i) 1,7
}

\begin{abstract}
- Additional supplemental material is published online only. To view, please visit the journal online (http://dx.doi. org/10.1136/bjophthalmol2020-318199)
\end{abstract}

For numbered affiliations see end of article.

\section{Correspondence to}

Dr lan Y Wong, Ophthalmology, University of Hong Kong, Hong Kong, Hong Kong; ianyhwong@gmail.com

MMZ and BNKC contributed equally.

$\mathrm{MMZ}$ and BNKC are co-first authors.

Received 28 October 2020 Revised 19 March 2021 Accepted 14 April 2021

\section{ABSTRACT}

Purpose To investigate the optic disc and peripapillary vessel density, as well as its ocular and systemic associations, in healthy eyes among adult Chinese population.

Methods A population-based cross-sectional eye survey was conducted on Chinese adults residing in Hong Kong. 1891 eyes from 1891 participants who completed $4.5 \times 4.5 \mathrm{~mm}$ optical coherence tomography angiography scans were recruited. Among the 1891 eyes, 404 were excluded due to low scan quality, optic disc or retinal disorders and non-Chinese ethnicity. The vessel densities (VDs) at nerve fibre layer plexus (NFLP) at both optic disc and peripapillary were collected for analysis. Multiple linear regression analysis was performed to determine the ocular and systemic associations of NFLP VD.

Results The study included 1487 participants (men: $41.2 \%$ ) with a mean age of $48.8 \pm 15.4$ years. The mean NFLP VD of the whole en face image, inside disc and peripapillary region was $53.8 \%, 42.7 \%$ and $60.3 \%$, respectively. In the multivariable model, decreased NFLP VDs were significantly associated with older age, male gender, longer axial length $(\mathrm{AL})$ and lower Signal Strength Index.

Conclusions This large population-based crosssectional study provided quantitative data of optic disc and peripapillary NFLP VD which may serve as a normative reference for clinical use. Apart from age, gender and $\mathrm{AL}$, the scan signal strength also should be taken into consideration during the assessment of NFLP VD.

\section{INTRODUCTION}

Glaucomatous optic neuropathy (GON), characterised by pathologic loss of retinal ganglion cell (RGC), is the leading cause of irreversible blindness in the world. ${ }^{1}$ Apart from raised intraocular pressure (IOP), there are abundant evidences suggesting that vascular insufficiency in the optic nerve head $(\mathrm{ONH})$ can attribute to the development of GON. ${ }^{2} 3$ Some studies even showed that vascular abnormalities arise earlier than retinal nerve fibre layer (RNFL) thinning and visual field defect. $^{45}$ Therefore, evaluation of blood perfusion at the site of optic disc might be of significance in the screening subjects with risk of developing glaucoma, and could be a potential site of treatment in the future.

There are four vascular networks in the retina. ${ }^{6}$ Among all these layers, nerve fibre layer plexus (NFLP, previously called radial peripapillary capillaries) is most popularly studied for its unique 'radial' distribution, which makes it more vulnerable and sensitive to ischemia condition than other retinal capillaries in the reticular formation. ${ }^{7} 8$ NFLP, from internal limiting membrane (ILM) to RNFL, is restricted to the microvasculature within the RNFL layer and is responsible for the nutritional supply of RGC axons. ${ }^{9} 10$ Therefore, evaluation of blood perfusion at NFLP is important both academically and clinically.

Optical coherence tomography angiography (OCTA) is a non-invasive and time-efficient imaging technique developed on the basis of OCT. OCTA detects the movement of red blood cells by measuring the changes from repeated OCT scans and generates three-dimensional (3D) angiographic information, allowing the clinicians to investigate the morphology and distribution of blood vessels in depth, as well as their interaction with the retinal layers. In addition, OCTA is able to synthesise qualitative images into quantitatively comparable values, such as vessel density (VD), using its own software. These advantages allow OCTA to be used in population-based fundus vascular studies quantitatively.

Currently, OCTA has been popularly used in the assessment of ONH perfusion. ${ }^{11} 12$ However, existing studies are all based in hospitals with potential selection bias and with limited sample size. Therefore, we conducted this populationbased study in eyes without optic nerve or retinal diseases among Chinese adults in Hong Kong, aiming to provide a normative reference for the clinicians to quantitively grade the OCTA data of $\mathrm{ONH}$ and peripapillary VD at NFLP slab, as well as explore the ocular and systemic associations of NFLP VD. If we could derive a population map of $\mathrm{ONH}$ and peripapillary NFLP VD, it might make OCTA a more popular diagnostic tool for early glaucoma, similar to RNFL measurement. 


\section{MATERIALS AND METHODS Participants}

The participants of this study were selected from the FAMILY Cohort. The FAMILY Cohort commenced recruitment since 2008 (https://familycohort.sph.hku.hk/en/), and randomly enrolled 19533 participants from 18 districts in Hong Kong. ${ }^{13}$ In this study, we randomly selected four among the 18 districts, namely Tin Shui Wai, Sham Shui Po, Kwun Tong and Tseung Kwan O. All adults aged 18 or above enrolled in the FAMILY cohort, residing in these four districts, were invited to participate by a registered mail. Participants who were pregnant or lactating, unable to understand and sign the consent, and/or failed to cooperate with OCTA scans were excluded.

In this study, 1891 participants with OCTA scans were recruited and only data from right eyes were used for data analysis. Data from 404 eyes were excluded (online supplemental figure 1) due to low OCTA scan quality, Signal Strength Index $(\mathrm{SSI}) \leq 45(\mathrm{n}=245)$, optic disc or retinal disorders $(\mathrm{n}=157)$ and non-Chinese ethnicity $(n=2)$. Only 1487 eyes without optic nerve or retinal disorders were enrolled for analysis.

\section{Ocular examination}

A $4.5 \times 4.5 \mathrm{~mm}$ scan centred on $\mathrm{ONH}$ was obtained with AngioVue software (V.2016.1.0.26) on RTVue XR Avanti spectral domain OCT (Optovue, Fremont, California, USA). The scan beam wavelength was $840 \pm 10 \mu \mathrm{m}$, the image acquisition rate was $70000 \mathrm{~A}$ scans/s. Each volume contained $304 \mathrm{~B}$ scan and each B scan contained 304 A scan. Each B scan was repeated two times and the system automatically generated an average. The automatic segmentation of ONH scan included NFLP slab, from ILM to outer limit of RNFL. In addition, the software automatically divided the optic disc into inside disc region and peripapillary region. The peripapillary region referred to a 0.75 $\mathrm{mm}$ wide elliptical annulus extending from the optic disc margin and was divided into six sectors, which were nasal, inferonasal, inferotemporal, superotemporal, superonasal and temporal sectors, based on the Garway-Heath map. ${ }^{14}$ The values of capillary density (excluding large vessels) from the whole en face image $(4.5 \times 4.5 \mathrm{~mm}$ scan region), inside disc and peripapillary in NFLP slab were collected for analysis. OCTA would be repeated if there was obvious motion artefacts. The images with obvious motion artefacts would be discarded.

Visual acuity was measured with the logarithm of the minimum angle of resolution chart (Lighthouse International, New York, USA) at a distance of $4 \mathrm{~m}$. Best corrected visual acuity was obtained based on subjective refraction. IOP was measured by non-contact tonometry (TONOREF II, Nidek, Gamagori, Japan) and an average of three consecutive readings was recorded. The central corneal thickness was measured with OPD-Scan III Wavefront Aberrometer (Nidek, Gamagori, Japan), while the anterior chamber depth and axial length (AL) were measured with AL-Scan (Nidek, Gamagori, Japan). In addition, dilated fundus examination was performed by an ophthalmologist using binocular indirect ophthalmoscopy and a slit lamp with a condenser lens (Digital Wide-Field Lens, Volk Optical, Ohio, USA).

\section{Systemic parameters}

The body mass index (BMI) was calculated with the formula: weight in $\mathrm{kg} /$ (height in $\mathrm{m})^{2}$. The waist circumference was also recorded for the abdominal obesity. The systolic blood pressure (SBP) and diastolic blood pressure (DBP) were measured with an automated sphygmomanometer (Hem-7000, Omron Corporation, Kyoto, Japan). The blood tests included cholesterol level,
Table 1 Demographic and ocular characteristics (right eye) of the study population

\begin{tabular}{|c|c|c|c|c|c|}
\hline Parameters & Number & Mean & SD & Minimum & Maximum \\
\hline Age & 1487 & 48.84 & 15.42 & 18 & 90 \\
\hline Male vs female & 1487 & 613 vs 874 & & & \\
\hline \multicolumn{6}{|l|}{ Eye-related parameters } \\
\hline BCVA (LogMAR) & 1481 & 0.00 & 0.12 & -0.26 & 0.78 \\
\hline $\mathrm{AL}(\mu \mathrm{m})$ & 1440 & 24.26 & 1.41 & 19.69 & 31.10 \\
\hline $\mathrm{CCT}(\mu \mathrm{m})$ & 1435 & 547.35 & 34.15 & 399.00 & 669.00 \\
\hline $\mathrm{ACD}(\mu \mathrm{m})$ & 1406 & 3.24 & 0.41 & 2.10 & 5.21 \\
\hline IOP $(\mathrm{mm} \mathrm{Hg})$ & 1470 & 13.66 & 2.74 & 6.30 & 23.30 \\
\hline SE (diopter) & 1476 & -1.36 & 2.81 & -16.25 & 9.75 \\
\hline SSI & 1487 & 63.17 & 9.20 & 45.08 & 88.45 \\
\hline \multicolumn{6}{|l|}{ Systemic-related parameters } \\
\hline BMI $\left(\mathrm{kg} / \mathrm{m}^{2}\right)$ & 1479 & 23.61 & 3.60 & 13.89 & 44.24 \\
\hline Waist circumference $(\mathrm{cm})$ & 1462 & 83.47 & 10.47 & 57.00 & 120.00 \\
\hline Prevalent HT vs absent & 1486 & 424 vs 1060 & & & \\
\hline Prevalent DM vs absent & 1300 & 139 vs 1159 & & & \\
\hline $\mathrm{SBP}(\mathrm{mm} \mathrm{Hg})$ & 1482 & 124.17 & 18.72 & 80.00 & 217.00 \\
\hline $\mathrm{DBP}(\mathrm{mm} \mathrm{Hg})$ & 1482 & 75.47 & 11.16 & 43.00 & 126.00 \\
\hline $\mathrm{HDL}$ (mmol/L) & 1286 & 1.50 & 0.65 & 0.65 & 19.50 \\
\hline $\mathrm{LDL}(\mathrm{mmol} / \mathrm{L})$ & 1286 & 3.19 & 0.95 & 0.85 & 7.34 \\
\hline $\mathrm{TG}(\mathrm{mmol} / \mathrm{L})$ & 1286 & 1.98 & 1.72 & 0.32 & 21.87 \\
\hline Creatinine $(\mu \mathrm{mol} / \mathrm{L})$ & 1286 & 68.95 & 33.01 & 6.00 & 1021.00 \\
\hline $\mathrm{HbA1C}(\%)$ & 1287 & 5.88 & 0.90 & 0.00 & 14.10 \\
\hline $\mathrm{HsCRP}$ (mg/L) & 1286 & 1.94 & 5.36 & 0.00 & 120.80 \\
\hline
\end{tabular}

$A C D$, anterior chamber depth; AL, axial length; BCVA, best corrected visual acuity; BMI, body mass index; $C C T$, central corneal thickness; DBP, diastolic blood pressure; DM, diabetic mellitus; HbA1C, glycated haemoglobin; $\mathrm{HDL}$, high-density lipoprotein; HsCRP, high-sensitivity C reactive protein; HT, hypertension; IOP, intraocular pressure; LDL, low-density lipoprotein; logMAR, logarithm of the minimum angle of resolution; SBP, systolic blood pressure; $\mathrm{SE}_{\text {, }}$ spherical equivalent; SSI, Signal Strength Index; TG, triglyceride.

high-density lipoprotein (HDL), low-density lipoprotein (LDL), triglyceride, glycated haemoglobin (HbA1C), and creatinine and high-sensitivity $\mathrm{C}$ reactive protein (HsCRP). For study purpose, in addition to self-reported medical history of hypertension and diabetes mellitus (DM), participants with SBP $\geq 140 \mathrm{~mm} \mathrm{Hg}$ or a DBP $\geq 90 \mathrm{~mm} \mathrm{Hg}$; and $\mathrm{HbA} 1 \mathrm{C} \geq 6.5 \%$ were also defined as having hypertension or DM, respectively.

\section{Statistical analysis}

Statistical analysis was performed using SPSS statistics V.26.0 (IBM SPSS). The data were presented in the form of mean, SD, 95\% CI for mean, minimum and maximum. Missing values were excluded from data analysis. Linear regression analysis was performed to determine the associations between the NFLP VD and ocular and systemic parameters. The ocular and systemic parameters with a $\mathrm{p}$ value less than 0.05 in the univariate analysis were enrolled into the multivariate regression analysis. A two-tailed $\mathrm{p}$ value less than 0.05 was considered as statistically significant.

\section{RESULTS}

One thousand four hundred and eighty-seven eyes from 1487 participants (men: 41.2\%) with a mean age of $48.8 \pm 15.4$, ranging from 18 to 90 years old, were enrolled for data analysis. Since there were some missing data in several specific parameters, for better interpretation of the results, the number of each parameters was shown in table 1 .

\section{The age-related and gender-related trend of NFLP VD}

The NFLP VD in the region of whole en face image, inside disc and peripapillary region was $53.8 \%$ (95\% CI, $53.57 \%$ to $53.92 \%)$, $42.7 \%$ (95\% CI, $42.27 \%$ to $43.15 \%)$ and $60.3 \%$ (95\% CI, $60.12 \%$ to $60.53 \%$ ), respectively. The values stratified by age and 
Table 2 The whole en face, inside disc and peripapillary vessel density (\%) at NFLP slab stratified by age and gender

\begin{tabular}{|c|c|c|c|c|c|c|}
\hline \multirow{2}{*}{$N(M / F)$} & \multicolumn{6}{|l|}{ Age group } \\
\hline & $18-29$ & $30-39$ & $40-49$ & $50-59$ & $60-69$ & $70-90$ \\
\hline \multicolumn{7}{|c|}{ NFLP_whole en face } \\
\hline All & 53.98 (53.61 to 54.35 ) & 54.61 (54.17 to 55.05 ) & 54.97 (54.63 to 55.32$)$ & 54.07 (53.77 to 54.37 ) & 52.50 (52.06 to 52.94$)$ & 50.78 (49.99 to 51.56$)$ \\
\hline Male & 53.09 (52.58 to 53.59$)$ & 54.25 (53.55 to 54.95$)$ & 53.97 (53.40 to 54.54$)$ & 53.53 (53.10 to 53.97$)$ & 52.13 (51.46 to 52.80$)$ & $50.10(49.10-51.10)$ \\
\hline Female & 54.71 (54.21 to 55.22 ) & 54.83 (54.25 to 55.41$)$ & 55.51 (55.09 to 55.93$)$ & 54.47 (54.06 to 54.88 ) & 52.74 (52.15 to 53.32$)$ & $51.50(50.27-52.74)$ \\
\hline \multicolumn{7}{|c|}{ NFLP_inside disc } \\
\hline All & 46.27 (45.30 to 47.24$)$ & 44.1 (42.67 to 45.53$)$ & 43.72 (42.74 to 44.71$)$ & 42.15 (41.34 to 42.95$)$ & 40.17 (39.2 to 41.14$)$ & $38.45(36.81-40.08)$ \\
\hline Male & 44.17 (42.59 to 45.74$)$ & 42.09 (39.85 to 44.34$)$ & 42.33 (40.76 to 43.89 ) & 42.34 (41.04 to 43.63$)$ & 40.33 (38.66 to 42.01$)$ & $37.05(35.04-39.06)$ \\
\hline Female & 47.97 (46.83 to 49.12$)$ & 45.33 (43.48 to 47.17 ) & 44.47 (43.21 to 45.73$)$ & 42.00 (40.98 to 43.03$)$ & 40.06 (38.88 to 41.24$)$ & $39.99(37.36-42.62)$ \\
\hline \multicolumn{7}{|c|}{ NFLP_peripapillary } \\
\hline All & 60.01 (59.57 to 60.46$)$ & 61.35 (60.78 to 61.93$)$ & 61.55 (61.19 to 61.91$)$ & $60.80(60.43$ to 61.17$)$ & 59.30 (58.76 to 59.84 ) & $57.26(56.27-58.24)$ \\
\hline Male & 59.34 (58.69 to 59.99 ) & 60.91 (60.07 to 61.76$)$ & 60.59 (60.00 to 61.18$)$ & 60.04 (59.53 to 60.55$)$ & 58.99 (58.20 to 59.78$)$ & $56.62(55.10-58.15)$ \\
\hline Female & 60.56 (59.95 to 61.17$)$ & 61.61 (60.84 to 62.39$)$ & 62.07 (61.63 to 62.51$)$ & 61.37 (60.86 to 61.88$)$ & 59.50 (58.77 to 60.23 ) & $57.94(56.69-59.19)$ \\
\hline
\end{tabular}

The data were shown in the form of mean $(95 \% \mathrm{Cl})$.

F, female; ILM, internal limiting membrane; M, male; NFLP, nerve fibre layer plexure, ranging from ILM to outer limit of nerve fibre layer.

gender are shown in table 2 and figure 1A. In general, the NFLP VD in female population is higher than that of male population. Inside the disc, an age-related decreasing trend in NFLP slab was observed, although a plateau occurred in the age from 30 to 59 years in men. In the peripapillary region, a slight increase in NFLP VD was observed from age 18 to 49 , then a sustained downward trend occurs starting from the age of 50 years.

\section{The distribution of NFLP VD in sectorial division of peripapillary region}

The distribution of NFLP VD in peripapillary regions was stratified by age. The details were shown in online supplemental table 1 and figure 1B. In general, the temporal region had a higher NFLP VD than the nasal region. The VD was highest in the superotemporal region, followed by inferotemporal region, while the lowest VD occurred in the nasal region, followed by superonasal region. However, the ranking of VD in inferior nasal and temporal region was not always constant throughout age.

\section{Ocular and systemic associations of NFLP VD}

With multiple linear regression analysis, a lower en face NFLP VD was significantly associated with older age $(0.34 \%$ decrease in VD per 10 years increase in age), male gender (1.01\% decrease in $\mathrm{VD}$ for male gender, compared with female), longer AL $(0.42 \%$ decrease in VD per $1 \mathrm{~mm}$ increase in AL) and SSI (0.19\% increase in VD per one unit increase in SSI). The details were shown in table 3 and representative images were shown in figure 2.

\section{DISCUSSION}

In this study, the whole en face image NFLP VD was reported to be $53.8 \%$, which was higher than $42.5 \%$ from Pinhas et al's study $^{15}$ (133 normal eyes from 133 individuals with a mean age of 41.5 years), but lower than the $58.8 \%$ from Kumar's study ${ }^{16}$ (74 normal eyes from 54 participants with a mean age of 51.2 years). The discrepancy might be caused by sampling bias, sample size, the setting of machine, as well as the data analysis software version. Since our study involved the greatest number of participants in the literature, the results should be representative and could be used as a reference in clinical practice.

Age-related or gender-related physiological changes should be taken into consideration when we want to determine whether the deviation from the normative values are pathological. Previous studies demonstrated that the NFLP VD in peripapillary and macula regions globally decreased with age. ${ }^{17}$ The results from this study are consistent with what that have been found in previous studies. Atherosclerosis, as a disease of ageing, characterised by thickening and narrowing of the arterial walls, might contribute to age-related decrease of NFLP VD in OCTA. The gender difference has been observed in blood flow velocity in $\mathrm{ONH}$ measured with laser speckle flowgraphy. ${ }^{19}{ }^{20}$ In this study, women was found to be an independent factor for higher
A

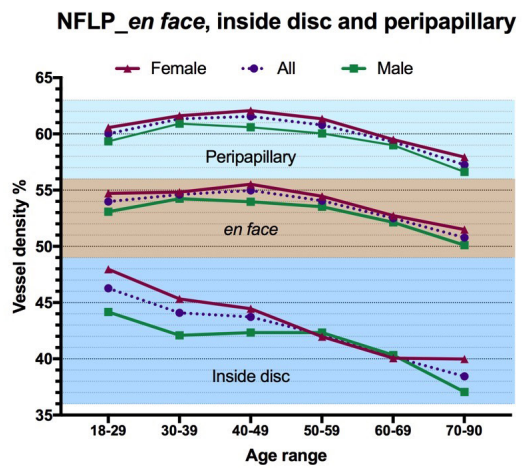

B

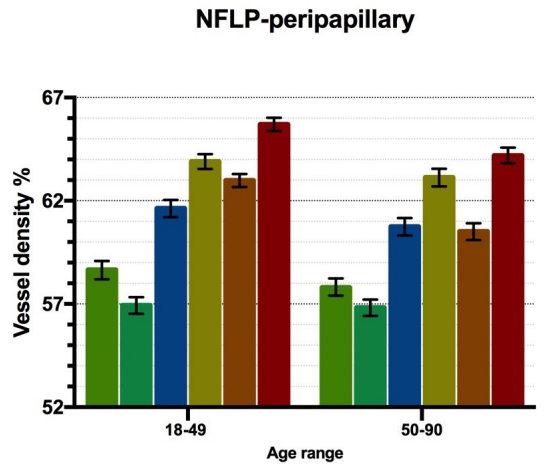

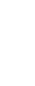

\section{(1)}


Table 3 The univariate and multiple regression analysis of whole image vessel density at NFLP slab

\begin{tabular}{|c|c|c|c|c|c|}
\hline \multirow[b]{2}{*}{ Parameters } & \multicolumn{2}{|c|}{ Univariate linear regression } & \multicolumn{3}{|c|}{ Multiple linear regression } \\
\hline & Beta $(95 \% \mathrm{Cl})$ & $P$ value & Beta* & Beta $(95 \% \mathrm{Cl})$ & $P$ value \\
\hline Per decade in age & $-0.53(-0.64$ to -0.42$)$ & 0.00 & -0.15 & $-0.34(-0.46$ to -0.22$)$ & 0.00 \\
\hline Male vs female & $-1.24(-1.58$ to -0.89$)$ & 0.00 & -0.15 & $-1.01(-1.32$ to -0.70$)$ & 0.00 \\
\hline \multicolumn{6}{|l|}{ Eye-related parameters } \\
\hline BCVA(LogMAR) & $-5.16(-6.62$ to -3.71$)$ & 0.00 & -0.02 & $-0.56(-1.97$ to 0.84$)$ & 0.43 \\
\hline Per $1 \mu \mathrm{m}$ in $\mathrm{AL}$ & $-0.48(-0.60$ to -0.35$)$ & 0.00 & -0.18 & $-0.42(-0.57$ to -0.28$)$ & 0.00 \\
\hline Per $1 \mu \mathrm{m}$ in CCT & $0.00(-0.01$ to 0.01$)$ & 1.00 & & & \\
\hline Per $1 \mu \mathrm{m}$ in $\mathrm{ACD}$ & $-0.11(-0.54$ to 0.33$)$ & 0.63 & & & \\
\hline Per $5 \mathrm{~mm} \mathrm{Hg}$ in IOP & $0.08(-0.25$ to 0.40$)$ & 0.64 & & & \\
\hline Per 1 dipolar in SE & $0.10(0.03$ to 0.16$)$ & 0.00 & 0.00 & $0.00(-0.07$ to 0.08$)$ & 0.93 \\
\hline Per 1 unit in SSI & 0.21 (0.20 to 0.23$)$ & 0.00 & 0.50 & $0.19(0.17$ to 0.20$)$ & 0.00 \\
\hline \multicolumn{6}{|l|}{ Systemic-related parameters } \\
\hline Per $5 \mathrm{~kg} / \mathrm{m}^{2}$ in BMI & $-0.08(-0.32$ to 0.17$)$ & 0.54 & & & \\
\hline Per $5 \mathrm{~cm}$ in WC & $-0.15(-0.24$ to -0.07$)$ & 0.00 & 0.04 & 0.07 (0.00 to 0.15$)$ & 0.07 \\
\hline Prevalent HT & $0.06(-0.32$ to 0.45$)$ & 0.74 & & & \\
\hline Prevalent DM & $-0.34(-0.95$ to 0.27$)$ & 0.27 & & & \\
\hline Per $10 \mathrm{~mm} \mathrm{Hg}$ in SBP & $-0.29(-0.39$ to -0.20$)$ & 0.00 & -0.04 & $-0.07(-0.19$ to 0.05$)$ & 0.22 \\
\hline Per $10 \mathrm{~mm} \mathrm{Hg}$ in DBP & $-0.17(-0.33$ to -0.01$)$ & 0.03 & 0.05 & $0.15(-0.03$ to 0.34$)$ & 0.11 \\
\hline Per $1 \mathrm{mmol} / \mathrm{L}$ in $\mathrm{HDL}$ & $-0.28(-0.57$ to 0.02$)$ & 0.07 & & & \\
\hline Per $1 \mathrm{mmol} / \mathrm{L}$ in $\mathrm{LDL}$ & $0.00(-0.20$ to 0.20$)$ & 0.97 & & & \\
\hline Per $1 \mathrm{mmol} / \mathrm{L}$ TG & $0.01(-0.10$ to 0.12$)$ & 0.82 & & & \\
\hline Per $1 \mu \mathrm{mol} / \mathrm{L}$ Creatinine & $-0.01(-0.01$ to 0.00$)$ & 0.10 & & & \\
\hline Per $1 \% \mathrm{HbA} 1 \mathrm{C}$ & $-0.18(-0.40$ to 0.03$)$ & 0.09 & & & \\
\hline Per $1 \mathrm{mg} / \mathrm{L}$ in HsCRP & $0.01(-0.03$ to 0.04$)$ & 0.79 & & & \\
\hline Model summary & 1 & & Adjuste & $p=0.00$ & \\
\hline
\end{tabular}

*Standardized beta coefficient.

ACD, anterior chamber depth; AL, axial length; BCVA, best corrected visual acuity; BMI, body mass index; BMI, body mass index; CCT, central corneal thickness; DBP, diastolic blood pressure; DM, diabetes mellitus; HbA1C, glycated haemoglobin; HDL, high-density lipoprotein; HsCRP, high-sensitivity C reactive protein; HsCRP, high-sensitivity C reactive protein; HT, hypertension; ILM, internal limiting membrane; IOP, intraocular pressure; LDL, low-density lipoprotein; logMAR, logarithm of the minimum angle of resolution; NFLP, nerve fibre layer plexure, ranging from ILM to outer limit of nerve fibre layer; ; $S B P$, systolic blood pressure; SE, spherical equivalent; SSI, Signal Strength Index; TG, triglyceride: WC, waist circumference.

NFLP VD. Generally speaking, women have a lower SBP and cardiac outputs, and thus may require more vascular network to ensure sufficient microcirculation to the organs. However, in this study, SBP was not independently associated with NFLP VD. The effects of oestrogen have been found to be associated with ocular haemodynamics. ${ }^{21}$ Whether it contributes to the gender difference of NFLP VD remains to be further studied.

The AL-related NFLP VD decrease is reasonable as myopia, especially high myopia, is associated with retinal microvascular network attenuation. However, comparing with our previous study, ${ }^{22}$ this time we found the impact of $\mathrm{AL}$ is much bigger on NFLP than that on macular superficial vascular complexes (SVC). This could be explained by the magnification effect induced by AL variation. In OCTA, the actual retinal diameter (Dt) is resized automatically to fit the output image size (Dm), which is fixed. ${ }^{23}$ According to Littman formula, ${ }^{2324} \mathrm{Dt}=p \cdot q \cdot \mathrm{Dm}$, where $p=3.48, q=0.01306 \cdot(\mathrm{AL}-1.82)$, the longer the AL, the larger scan area will be covered by the OCTA scan. In disc area, the NFLP VD markedly decreased with distance from the disc margin. ${ }^{25}$ Therefore, as AL increase, the magnification effect will aggravate the NFLP VD decrease. In macular area, the nasal side SVC VD increases in peripheral area (closer to disc), while the temporal side SVC VD decreases in peripheral area (further from disc), ${ }^{26}$ so 'magnification leading to VD decrease' effect was partially cancelled by the nasal side.

IOP is a well-recognised risk factor for the development and progression of glaucoma. However, no correlation between IOP and NFLP VD was found in this study. This might be because all glaucoma or glaucoma suspect participants were excluded, and only five participants had an IOP slightly over than $21 \mathrm{~mm} \mathrm{Hg}$ were enrolled. It has been reported that moderate IOP elevation would not have significant impact on retinal microcirculation due to autoregulation of blood flow. ${ }^{27}$ Therefore, such small degree of IOP increase in this study is unlikely to compromise vascular supply to NFLP.

In this study, we also found that a higher SSI was associated with a higher NFLP VD in the regression model. Furthermore, among all the significantly independent variables, SSI had the
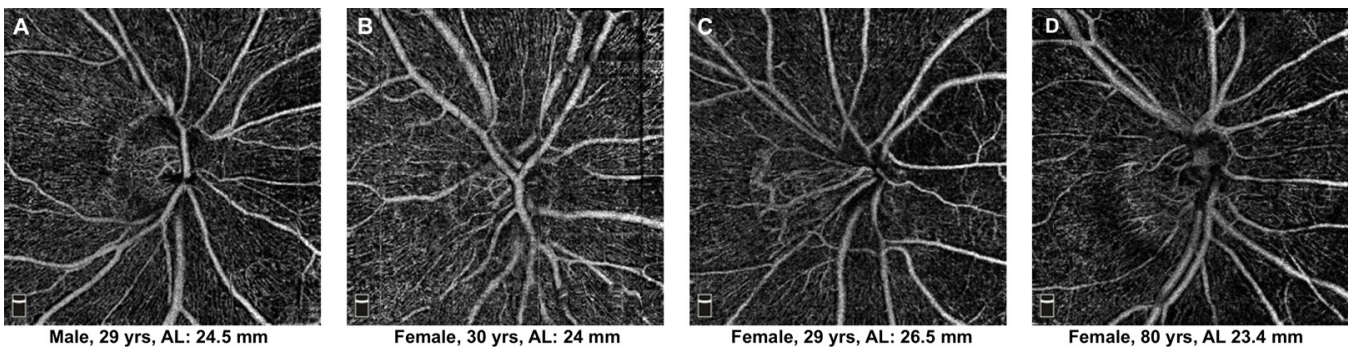

Figure 2 Representative OCTA images showing the differences of whole image vessel density at NFLP slab among gender, age and axial length $(A \& B)$ indicates gender-related difference; $(B \& C)$ indicated $A L$-related difference; $(B \& D)$ indicated age-related difference. NFLP, nerve fibre layer plexure; OCTA, optical coherence tomography angiography. 
strongest effect in the prediction NFLP VD in participants of different age groups. These results were consistent with our previous study, ${ }^{22}$ suggesting that we must take SSI value into consideration when comparing retinal $\mathrm{VD}$ values.

Although obesity was found to be associated with reduction of retrobulbar blood flow velocity, ${ }^{28}$ our results did not suggest any correlation between BMI nor waist circumference and NFLP VD. In this study, there were only $70(5 \%)$ participants having a BMI $\geq 30 \mathrm{~kg} / \mathrm{m}^{2}, 25(5 \%)$ men having a waist circumference $>102 \mathrm{~cm}$ and $204(23 \%)$ women having a waist circumference $>88 \mathrm{~cm} .{ }^{29}$ Since most of the participants enrolled in this study did not have obesity, the results might not be able to explore the correlation between VD and obesity. In further study, a more balanced sample size in both obese and non-obese group will have stronger power in investigating the association of obesity and NFLP VD.

In addition to obesity, other vasculopathic risk factors like hypertension, hyperglycaemic and hyperlipidemia are possible public health conditions which may be closely correlated with ocular microcirculation. ${ }^{29-34}$ However, results in our study did not suggest presence of hypertension, DM, elevated SBP or DBP or HbA1C or serum lipids were independently associated with the decrease of NFLP VD. The difference of sample size, inclusion criteria and race potentially contributed to the discrepancies in results. Although our study did not find any positive results, the influence of hypertension, hyperglycaemic and hyperlipidemia on ocular microcirculation should not be ignored in clinic.

A potential limitation is the sampling frame enrolled complete households in which all adult members agreed to participate, thus potentially being susceptible to selection bias. However, the 'healthy volunteer effect' could still have occurred if individuals were sampled instead of recruitment from a familybased cohort. ${ }^{13}$ Another limitation is the wide AL range from $19.69 \mu \mathrm{m}$ to $31.10 \mu \mathrm{m}$. The AL-related magnification may vary scan area, thereby exaggerating the NFLP VD decrease as AL increase. In addition, image artefacts remains an inherent challenge of OCTA image quality due to how OCTA is operated and how OCTA data is processed and displayed. Even though we have taken precautions to reduce the image artefacts, which were mainly caused by eye movements, ocular pathology, and low vision ${ }^{35}$; segmentation artefacts could not be totally avoided as high myopic eyes were included for analysis. We did not exclude eyes with high myopia because these eyes were not found to have pathological changes with dilated fundal examination. In addition, since the aim of this study is to evaluate the normative reference of ONH and peripapillary VD at NFLP slab in the general population, not only in eyes with normal AL, we think it is more appropriate to include highly myopic eyes without obvious pathological changes as well. The artefacts in this study should be negligible since we are gathering a big pool of data to identify the normative value. Nonetheless, when it is applied to individual case analysis, the doctor should look closely for any possible reasons for the OCTA to be unreliable (such as segmentation and centration problems), just like how we interpret OCT images. Lastly, since our study covered a wide age range, although we had a sample size of 1487 , comparing to other population-based studies, the sample size was relatively small when stratified with age. Nonetheless, to our knowledge, our study is the largest series in evaluating the optic disc VD in participants without fundus pathology.

In conclusion, this study provided population-based quantitative data on the optic disc and peripapillary NFLP VD evaluated by OCTA in adult Chinese without fundus pathology. With the largest sample size in literature and age span, the data was stratified by age and gender to provide age-related and genderrelated reference values for clinical use. With the regression analysis, we also found that NFLP VD among eyes with normal fundus was only significantly and independently associated with age, gender, AL and SSI, but not associated with IOP, SE, obesity, hypertension, DM or any other ocular or systemic parameters. Clinicians should take into account of these factors which might affect the findings of NFLP VD.

\section{Author affiliations}

${ }^{1}$ Ophthalmology, University of Hong Kong, Hong Kong, Hong Kong

${ }^{2}$ Oregon Health \& Science University Casey Eye Institute, Portland, Oregon, USA

${ }^{3}$ Ophthalmology, University of Hong Kong Li Ka Shing Faculty of Medicine, Hong Kong, Hong Kong

${ }^{4}$ School of Public Health, University of Hong Kong, Hong Kong, Hong Kong

${ }^{5}$ The State Key Laboratory of Brain and Cognitive Sciences, University of Hong Kong, Hong Kong, Hong Kong

${ }^{6}$ School of Public Health, LKS Faculty of Medicine, University of Hong Kong, Hong Kong, Hong Kong

${ }^{7}$ Ophthalmology, Hong Kong Sanatorium and Hospital, Hong Kong, Hong Kong

Contributors MMZ and BNKC contributed to research design, data acquisition, data analysis and manuscript preparation; QSY contributed to data analysis and manuscript preparation; JCHC, ALKN, KS, JJCC, JKWW and JS contributed to data acquisition; MYN contributed to data acquisition, data analysis and manuscript preparation; GML and JS-ML contributed to data acquisition; IYW contributed to research design and data acquisition.

Funding The present study is supported by part of the 'Chloe Ho Safeguarding Vision Initiative' and was funded by the Jessie \& George Ho Charitable Foundation. The establishment of the original cohort was funded by the Hong Kong Jockey Club Charities Trust from 2007 to 2014.

Competing interests None declared.

\section{Patient consent for publication Obtained.}

Ethics approval The population-based cross-sectional study was approved by the Institutional Review Board of the University of Hong Kong (UW 16-2038) and conducted in accordance with the principles of Declaration of Helsinki. Written informed consent was obtained prior to the examination.

Provenance and peer review Not commissioned; externally peer reviewed. Data availability statement Data are available upon reasonable request.

Supplemental material This content has been supplied by the author(s). It has not been vetted by BMJ Publishing Group Limited (BMJ) and may not have been peer-reviewed. Any opinions or recommendations discussed are solely those of the author(s) and are not endorsed by BMJ. BMJ disclaims all liability and responsibility arising from any reliance placed on the content. Where the content includes any translated material, BMJ does not warrant the accuracy and reliability of the translations (including but not limited to local regulations, clinical guidelines, terminology, drug names and drug dosages), and is not responsible for any error and/or omissions arising from translation and adaptation or otherwise.

Open access This is an open access article distributed in accordance with the Creative Commons Attribution Non Commercial (CC BY-NC 4.0) license, which permits others to distribute, remix, adapt, build upon this work non-commercially, and license their derivative works on different terms, provided the original work is properly cited, appropriate credit is given, any changes made indicated, and the use is non-commercial. See: http://creativecommons.org/licenses/by-nc/4.0/.

\section{ORCID iDs}

Ming Ming Zhu http://orcid.org/0000-0003-0221-2325

Bonnie N K Choy http://orcid.org/0000-0002-9740-3935

Jonathan Cheuk Hung Chan http://orcid.org/0000-0002-0177-8178

Alex L K Ng http://orcid.org/0000-0002-8321-5634

Janice Jing Chee Cheung http://orcid.org/0000-0003-1216-729X

Jasper Ka Wai Wong http://orcid.org/0000-0003-4039-5468

lan Y Wong http://orcid.org/0000-0002-5328-1796

\section{REFERENCES}

1 World Health Organization (WHO). Consultation on public health management of chronic eye diseases: report of a WHO consultation 2011.

2 Flammer J, Orgül S, Costa VP, et al. The impact of ocular blood flow in glaucoma. Prog Retin Eye Res 2002;21:359-93. 
3 Hayreh SS. Blood flow in the optic nerve head and factors that may influence it. Prog Retin Eye Res 2001;20:595-624.

4 Chen C-L, Bojikian KD, Wen JC, et al. Peripapillary retinal nerve fiber layer vascular microcirculation in eyes with glaucoma and Single-Hemifield visual field loss. JAMA Ophthalmol 2017;135:461-8.

5 Lu P, Xiao H, Liang C, et al. Quantitative analysis of microvasculature in macular and peripapillary regions in early primary open-angle glaucoma. Curr Eye Res 2020;45:629-35.

6 Campbell JP, Zhang M, Hwang TS, et al. Detailed vascular anatomy of the human retina by Projection-Resolved optical coherence tomography angiography. Sci Rep 2017;7:42201.

7 Alterman M, Henkind P. Radial peripapillary capillaries of the retina. II. Possible role in Bjerrum scotoma.Br. J. Ophthalmol 1968;52:26-31.

8 Kornzweig AL, Eliasoph I, Feldstein M. Selective atrophy of the radial peripapillary capillaries in chronic glaucoma. Arch Ophthalmol 1968:80:696-702.

9 Scoles D, Gray DC, Hunter JJ, et al. In-Vivo imaging of retinal nerve fiber layer vasculature: imaging histology comparison. BMC Ophthalmol 2009;9:9.

10 Grzybowski A, Barboni P. Oct and imaging in central nervous system diseases: the eye as a window to the brain. 2020. 2nd edn. Cham: Springer International Publishing, 2020.

11 Mammo Z, Heisler M, Balaratnasingam C, et al. Quantitative optical coherence tomography angiography of radial peripapillary capillaries in glaucoma, glaucoma suspect, and normal eyes. Am J Ophthalmol 2016;170:41-9.

12 Mansoori T, Sivaswamy J, Gamalapati JS, et al. Radial peripapillary capillary density measurement using optical coherence tomography angiography in early glaucoma. J Glaucoma 2017:26:438-43.

13 Leung GM, Ni MY, Wong PT, et al. Cohort profile: family cohort. Int J Epidemiol 2017:46:e1.

14 Garway-Heath DF, Poinoosawmy D, Fitzke FW, et al. Mapping the visual field to the optic disc in normal tension glaucoma eyes. Ophthalmology 2000;107:1809-15.

15 Pinhas A, Linderman R, Mo S, et al. A method for age-matched OCT angiography deviation mapping in the assessment of disease- related changes to the radial peripapillary capillaries. PLoS One 2018;13:e0197062.

16 Kumar RS, Anegondi N, Chandapura RS, et al. Discriminant function of optical coherence tomography angiography to determine disease severity in glaucoma. Invest Ophthalmol Vis Sci 2016;57:6079-88.

17 Nelson AJ, Chang R, LeTran V, et al. Ocular determinants of peripapillary vessel density in healthy African Americans: the African American eye disease study. Invest Ophthalmol Vis Sci 2019:60:3368-73.

18 Jo YH, Sung KR, Shin JW. Effects of age on peripapillary and macular vessel density determined using optical coherence tomography angiography in healthy eyes. Invest Ophthalmol Vis Sci 2019;60:3492-8.

19 Yanagida K, Iwase T, Yamamoto K, et al. Sex-Related differences in ocular blood flow of healthy subjects using laser speckle Flowgraphy. Invest Ophthalmol Vis Sci 2015;56:4880-90
20 Iwase T, Yamamoto K, Yanagida K, et al. Investigation of causes of sex-related differences in ocular blood flow in healthy eyes determined by laser speckle flowgraphy. Sci Rep 2017;7:13878.

21 Toker E, Yenice 0, Akpinar I, et al. The influence of sex hormones on ocular blood flow in women. Acta Ophthalmol Scand 2003;81:617-24.

22 You QS, Chan JCH, Ng ALK, et al. Macular vessel density measured with optical coherence tomography angiography and its associations in a large population-based study. Invest Ophthalmol Vis Sci 2019;60:4830-7.

23 Sampson DM, Gong P, An D, et al. Axial length variation impacts on superficial retinal vessel density and foveal avascular zone area measurements using optical coherence tomography angiography. Invest Ophthalmol Vis Sci 2017;58:3065-72.

24 Bennett AG, Rudnicka AR, Edgar DF. Improvements on Littmann's method of determining the size of retinal features by fundus photography. Graefes Arch Clin Exp Ophthalmol 1994;232:361-7.

25 Jia Y, Simonett JM, Wang J, et al. Wide-Field OCT angiography investigation of the relationship between radial peripapillary capillary plexus density and nerve fiber layer thickness. Invest Ophthalmo/ Vis Sci 2017:58:5188-94.

26 Lavia C, Mecê P, Nassisi M, et al. Retinal capillary plexus pattern and density from fovea to periphery measured in healthy eyes with Swept-Source optical coherence tomography angiography. Sci Rep 2020;10:1474.

27 Zhang Q, Jonas JB, Wang Q, et al. Optical coherence tomography angiography vessel density changes after acute intraocular pressure elevation. Sci Rep 2018;8:6024.

28 Cekiç B, Toslak İclal Erdem, Doğan B, et al. Effects of obesity on retrobulbar flow hemodynamics: color Doppler ultrasound evaluation. Arq Bras Oftalmol 2017:80:143-7.

29 Janssen I, Katzmarzyk PT, Ross R. Body mass index, waist circumference, and health risk: evidence in support of current National Institutes of health guidelines. Arch Intern Med 2002;162:2074-9.

30 Chua J, Chin CWL, Hong J, et al. Impact of hypertension on retinal capillary microvasculature using optical coherence tomographic angiography. J Hypertens 2019;37:572-80

31 Donati S, Maresca AM, Cattaneo J, et al. Optical coherence tomography angiography and arterial hypertension: a role in identifying subclinical microvascular damage? Eur J Ophthalmol 2021:31:158-65

32 Cao D, Yang D, Yu H, et al. Optic nerve head perfusion changes preceding peripapillary retinal nerve fibre layer thinning in preclinical diabetic retinopathy. Clin Exp Ophthalmol 2019;47:219-25.

33 Leung H, Wang JJ, Rochtchina E, et al. Dyslipidaemia and microvascular disease in the retina. Eye 2005;19:861-8.

34 Owen CG, Rudnicka AR, Welikala RA, et al. Retinal Vasculometry associations with cardiometabolic risk factors in the European prospective investigation of CancerNorfolk study. Ophthalmology 2019;126:96-106.

35 Spaide RF, Fujimoto JG, Waheed NK. Image artifacts in optical coherence tomography angiography. Retina 2015;35:2163-80. 